\title{
Principles of Cosmic Thinking as the Basis of Holistic Research Approach
}

\section{Svyatokhina G. B}

\author{
Associate Professor, Doctor of Philosophy, Ufa State University of Economics and Services, Russia
}

Email: svjatog@mail.ru

\section{Doi:10.5901/mjss.2015.v6n5s1p589}

\begin{abstract}
This article pursues the aim of understanding the philosophical principles of the Russian cosmists and the Teaching of Living Ethics with regard to solving the problem of the holistic approach. The research shows that the methodological principle of Three-Hypostasis Essence of the Absolute forming the basis of cosmism provides new opportunities for an integral systemic understanding of Being - in the unity of its ontological, epistemological and axiological aspects. Including in the structure of its body not only empiric and rational capabilities of man's world perception but as well spiritual ones, relating to heart activity, the proposed approach provides the grounds for a deeper systemic vision of the world and man in it. It allows to understand the algorithm of natural evolutional dynamics of cosmic Being, work out methodological principles of integral systemic understanding of the world, and conceive the significance and urgency of man's spiritual development. On the whole, the acquisition and practical application of philosophical principles of cosmic thinking will create the preconditions for evolutional cosmic development of man and society.
\end{abstract}

Keywords: cosmic thinking, a holistic approach, synthesis, Three-Hypostasis Essence of the Absolute, the Non-manifested Being, the Manifested Being.

\section{Introduction. The Actuality of the Research}

Modern scientific trends in their essence appear as separate views at the Single Reality from different angles. Moreover, many research methods and methodologies used remain uncoordinated. Their verity as well as the verity of the results obtained is relative, so it is not always in full compliance with practice. Global crises in all spheres of human life are plain evidence of this fact. It is urgent today to try to comprehend the problems of research methodologies in natural and social science as well as the Humanities from the angle of the systemic holistic approach (HA).

This article pursues the aim of understanding the philosophical principles of the Russian cosmists and the Teaching of Living Ethics with regard to solving the problem of the holistic approach. In this context it is important to realize the algorithm of the natural evolutional dynamics of cosmic Being stemming from the Absolute Foundations, to comprehend the synthetic integrity of its ontological, epistemological and axiological aspects, to point out the basic methodological principles of the holistic systemic understanding of the world and the peculiarities of its research tools; to perceive the role and significance of spiritual perfection of man for his cosmic evolution.

The tradition presupposing understanding the world and man in it, in the context of total unity is widely represented in the world philosophical thought. The Upanishads (Upanishads, 1992) and "I-Ching" (Torchinov, 2005) are among the earlier doctrines devoted to this issue. The most outstanding names among the philosophers directed at the holistic approach are Heraclitus (Viller, 2002; pp. 28-37), Parmenides (Viller, 2002, pp. 38-43), Pythagoras (Viller, 2002, pp. 2227), Plato (Viller, 2002, pp. 46-103), Neo-Platonists (Viller, 2002: Plotinus, pp. 162-189; lamblichus, pp. 194-197; Marius Victorinus, pp. 198-203), N. Cusa (Viller, 2002, pp. 318-335), J. Boehme (Boehme, 1990) and others. But the successfully developing young science of the New Age moved the HA principles to the background. The historic circumstances were such that science started to use the principles of abstract thinking (logical monism according to S.N. Bulgakov (Bulgakov, 1993) in its research methodology and in natural science cognition; in particular, a rationalistic objectivistic approach was developed. Later the tradition of abstract thinking revealed in social science and the Humanities as well, though with regard to the irrational aspect of being. There emerged a problem of harmonization of methods and criteria of verity used in natural and social science. In the XXth century, many researchers paid serious attention to solving numerous cognitive tasks. In XX century these ideas enjoyed a great deal of attention with many scientists, philosophers and researchers, T. Kuhn (Kuhn, 2002), I. Lakatos (Lakatos, 2002), K. Popper (Popper, 2005), A. Einstein (Einstein, 1967), W. Heisenberg (Heisenberg, 2005), N. Bohr (Bohr, 1961), P. Feyerabend (Feyerabend, 1986), G. Follmer (Follmer, 1998) and many others being among them. 
However, even today the problem of searching a holistic integral research methodology remains topical. Many scientists (Mikeshina, 2006; Taisina, 2013; Ilyin, 2006) provide corroboration to this fact. For example, F. V. Lazarev and $\mathrm{S}$. A. Lebedev write that reaching a consensus among natural, social sciences and the Humanities is "an undertaking that is by order of magnitude more complex as compared to natural science and mathematical sciences" (Lazarev \& Lebedev, 2006, p. 68). In this article, the author offers some suggestions on how to resolve this problem.

\section{Russian Philosophy and the Teaching of Living Ethics on HA Peculiarities}

In the context of seeking the solution to the problem of a holistic research approach developed in the Russian original philosophy is worth paying due attention to. The most prominent names among Russian "cosmic thinking" philosophers and scientists of the XIX-XX centuries who studied the problem of total integrity and HA are V. S. Soloviev (Soloviev, 1999), H. P. Blavatskaya (Blavatskaya, 1992), S. N. Bulgakov (Bulgakov, 1993), P. A. Florensky (Florensky, 2003; Florensky, 2001), N. A. Berdyaev (Berdyaev, 1994) etc. In the XX century, this tradition got its most accomplished expression in The Teaching of Living Ethics (The Teaching of Living Ethics: 2003, 2004, etc.): the philosophy of cosmic thinking connected with the names of H. I. Roerich (Roerich H. I., 2000; Letters of Helena Roerich., 2012) and N. K. Roerich (Roerich, N. K., 1995, 1996). Being a synthesis of scientific achievements, art, religious and philosophical ideas both of the East, and of the West, based on the Russian spiritual culture, the Teaching of Living Ethics reflected an integral systemic conception of the Bases of Being and the structure of the Universe arising from them. On the one hand, these basic principles of the philosophy of cosmic thinking handed down to us the conception of harmonious integrity of practical, moral and aesthetical rules and norms of Cosmic Being. On the other hand, by means of developing a system of categorical and conceptual apparatus, they lay the foundations of synthesis of research methodologies. Among the contemporary researchers in the field of cosmic thinking we should note such researchers as L. V. Shaposhnikova (Shaposhnikova, 2004, 2005), A. A. Lebedenko (Lebedenko, 2010), etc.

At its early stage of development Russian philosophy would express its integral perception of the world by means of art and inner spiritual creativity. It was later, in XIX century that this tradition got its systemic and structural shaping. To express this way of spiritual synthetic worldview a relevant categorical language was needed. Such synthetic categories as zhivoe znanie (live knowledge), conciliarism, wholeness, total integrity and others rank as most important in it (Maslin, (Ed.), 2007). Later they were supplemented with such categories as Living Ethics, Teacher, Grain of Spirit, Cosmic Magnet, Spiritual Cosmic Hierarchy and others (Avotina, 2011).

The specificity of synthetic thinking also manifested itself in the fact that in the XIX - early XX centuries in Russian philosophical thought alongside with Russian Cosmism emergence as an HA in understanding cosmic Being there developed another trend named "The Philosophy of Heart". Even its name implied a special synthetic organ of perception of the world - Heart, the meaning of which for man's life has not yet been understood to the full extent. In the framework of this approach based on the analysis of biblical and philosophical texts, Heart was shown as revealing its new sides and potentialities, in particular, being the coordination centre of all spheres of man's life (bodily, psycho-emotional, intellectual, spiritual). To generalize the above stated let us cite the words of V.F. Voyno-Yasenetsky, a famous surgeon and priest:

Heart is mentioned on every other page of the Bible $<\ldots>$ this word is not only attributed the meaning of the central sense body but is also referred to as the most important means of cognition, comprehension and perception of spiritual influence. Moreover, according to Holy Scripture, Heart is a means of communication between man and God, hence it is a means of superior cognition (Voyno-Yasenetsky, Chapter 2).

Living Ethics, trying to understand the potentialities of heart as a special systemic and structural energy centre of life even on a Cosmic Being scale, reveals its unique potentialities to be the communication centre with analogous centres of life in Cosmic Reality including those possessing a hierarchically higher level of spiritual development up to the Bases of the Universe. A quotation from "Hierarchy" clearly illustrates this:

Likewise the heart should be understood as the unique natural link between the visible and invisible worlds. Many secretions bind the lowest strata of both worlds, but only the thread of the heart can lead into the Infinite. In this lies the difference between magic and the nature of spirit. Thus, I advise, first of all, to pay attention to the heart as the source of the predestined unification of the worlds. It should not be thought that Hierarchy is only discipline; it is the advance into the Higher World" (The Teaching of Living Ethics, Hierarchy, 2011, pp. 217-218).

In connection with this, L. V. Shaposhnikova writes: "Heart is a crossroads where spirit and matter, different reality and our world, the heavenly and the earthly meet" (Shaposhnikova, 2005, p. 34).

Thus, a deep understanding of such a systemic and structural specificity of Heart in Cosmic Being opens up the possibilities of new methods of cognition by the use of spiritually developed Heart as an organ of synthetic perception of the world. But this potentiality of Heart that sometimes gives notice of itself in ordinary life may develop into conscious 
cognition as its spiritual development and improvement progresses.

\section{Relevant Principles of the Philosophy of Cosmic Thinking}

A limited volume of this article does not allow to set a task of thorough analysis of HA problem. So, this paper only presents some principal generalized results of multiannual creative research. Some of the ideas have been enunciated by the author in a number of articles and reports. (Galina Svyatokhina, 2013, p. 709; 2013, pp. 133-138; 2015) These publications present a more detailed analysis of the suggested holistic synthetic approach. Thereat, the author has no claims on the finality of the problem solution but presents the way it is currently understood at the principle level. It is noteworthy that the research applies the terminology that is used in the original sources or has proved to be the most suitable for describing connections and relations of reality in this context. It is also of importance to take into consideration the specific characteristics of HA synthetic categorical and conceptual apparatus. It represents not a conventional formally logical abstract aspect of reality but an integrated with ethical, aesthetical, spiritual and practical components concrete potential of an action and interaction with the surrounding world. Thus, HA categorical apparatus presupposes participation of both man's intellectual abilities and heart as the organ of synthetic world perception. This means that human heart, due to its direct energetic relation with the Basis of Being, possesses the ability to lay the background of optimal (from the angle of true cosmic Being) practical task solution with due regard to the axiological aspect.

Let us consider some key principles of the philosophy of cosmic thinking which are important to take into consideration when developing a synthetic research methodology. In connection with this, an example of Bulgakov's judgements concerning the differences between the principles of holistic research approach and the tradition of abstract thinking is worth mentioning. Thus, in search of an acceptable integral way to express the essence of the ThreeHypostases structure of the Foundations of Being, S. N. Bulgakov (Bulgakov, 1993) finds it in the basic structure of sentence, in the interrelated triune integrity of the subject, the predicate and the linking verb. He stresses that, in the same way as in the sentence "concealing the manner of triunity" the essential relationship among its structural elements must be observed in order to preserve its meaning, it must not be broken with respect to the Foundations of Being as well. Otherwise the essential triune relationship will "oppose any monism of the philosophy of identity" which tends to "dissolve all the three components reducing them to one: either the subject, or the predicate, or the linking verb", either inferring everything from it or reducing everything to it" in the end. According to S. N. Bulgakov, this "deduction" turns into an unsolvable difficulty for "philosophizing thought". By way of stressing that "the foundation of Being is not singular but triple in integrity, or triune" he means the following specificity of development of its different hypostases. "Hypostasis, or person, or I exists in possession of its own nature, that always tells but never utters its revelation in full, which it realizes as its own Being (in various nuances and modalities). "Substance" exists not only "by itself, as a subject" but also "for itself, as a predicate", both "by itself and for itself" in liaison as objective reality. And all these three fundamentals are not only dialectical elements of the one, simplifying and withdrawing each other in the synthesis, but three simultaneous and equal foundations, roots of the objective reality so to say, in their totality being the life of substance" (Bulgakov, 1993, $p$. 319). To get a more clear-cut idea of "the life of substance" or the essential dynamics of the Absolute, which is urgent for a synthetic research methodology, let us supplement it by Roerich's utterance. According to her, "The Absolute contains the notions of the Non-Manifested and the Manifested. Only the Manifested Cosmos may reveal its potential unlimitedly" (Roerich H. I., 2000, p. 252.) Thus, trying to find the purport of the ideas presented in the works by the above mentioned and other philosophers and scientists, especially in the Teaching of Living Ethics, resulted in this kind of understanding of the way of solving the problem.

While trying to understand the philosophical problems of Being it is crucial to approach them taking into account the Three-Hypostases Essence of Being which realizes its potentialities in Eternity and Unlimitedness according to the principle "Itself, by Itself, in Itself". This approach not only explains the essential content of the Absolute Being but also provides with an algorithm of dynamics in their unity. Hence a conclusion can be made that in the context of the holistic approach used in cosmic thinking comprehending the range of problems requires considering them in triunity of ontological, epistemological and axiological angles. Let us present it symbolically in the following way.

The Hypostases can be defined as mutually conditioned in Eternity and Unlimitedness Principles of the Absolute, or the Absolute I: Life, Mind and Love. Thereat Absolute I is perceived as a centre, or Heart, of a self-organizing integrity in Eternity and Infinity.

The Absolute Principle of Life (the ontological aspect) which is in harmony with the concept of "integrity" is only realized in Triunity through the Hypostases of Mind and Love. In this context, Mind (the epistemological angle) appears as a logical and structural form of the integral Life Cycle realized by the algorithm of double negation of the type "I - not-I - not-not-l" , or symbolically designated as a system with full feedback (Razumov \& Blagodatskikh, 2006, p. 267). In 
reality such an algorithm can only work on the basis of spiritual, giving life to everything and uniting all energetic nature of the Absolute I or God, which equals to Love (axiological aspect). By its spiritual nature Love ensures a harmonious unity and integrity of the Single including the dynamic of its manifestations in Eternity and Unlimitedness. We can find an example of understanding the nature of God as Love in works by P. A. Florensky: "God is Love..., i.e. love is the godly essence, its true nature" (Florensky, 2003, p. 83).

Being a universal substance in the Eternity and Infinity of its potential, the Absolute is both the Source of all the manifested, and the Outcome of all, or the purpose and the criterion of the true manifested Being. Hence, it is Love, as the nature of God and the Absolute, that appears to be the criterion of true Being, and its manifestation in the practice of life is a prerequisite for the cosmic evolution of mankind. Another conclusion may be driven out. The Source, the Outcome, and Manifested Being in their unity form a cycle of manifestation of the Essence of the Absolute, or the principle of Helical Movement of the universal energy of Love. Thus, according to H. P. Blavatskaya, the basis of this dynamical way of the integral self-organizing Single Reality is constituted by the principle of Eternal Vibration in the Unmanifested which is transformed into a Helical Movement in the phenomenal or manifested World (Blavatskaya, 1992, Vol. 1, b. 1, p. 167).

Its essence consists in the following. The Three-Hypostases Essence of Absolute Reality in Manifested Being acquires a septenary structure of expression due to the dual nature or binary opposition of Manifested Being. That is, the essence of integrity retains its Three-Hypostases character as a principle derivative from the Foundations of Being. But as for the manifested centres of life, or Monads, as integrities of phenomenal world, they already possess a septenary structural organization presupposing the whole range of possible states of qualitative expression of the Hypostases including their combinations. Life and death, love and hatred, beauty and ugliness, harmony and disharmony, creation and destruction, etc. can serve as examples. This takes place due to emergence of opposite poles. According to H. P. Blavatskaya, "To get a more clear-cut understanding of figure seven it should be added that not only figure seven rules over the periodicity of life phenomena but also heads the series of chemical elements and dominates in the world of sound and colour, as the spectroscope reveals it" (Blavatskaya, 1992, Vol. 2, b. 4, p. 788).

In connection with this, Roerich H. I. put forward and idea that "The whole life is vibration, which means that life forms or differentiations are born and develop due to different velocity of vibrations of begotten state of substance which is spiritual in its essence." (Roerich H. I., 2000, p. 239).

Thus, this approach allows to understand that due to the principle of the Three-Hypostases Essence every cycle of man's aspirations leads to either an evolutional (creative), or involutional (destructive) result depending on the account taken of the integral structure of Being as a system with a dual feedback and the quality of effort made (i.e. positive or negative sign of the feedback).

In this connection, H. I. Roerich writes:

Love alone reveals all concealed fires. Thus, in the foundation of each creation is laid the great Attraction, the great Love. All that is in the world depends on love and is sustained by love. Love must lead to the higher comprehension" (Letters of Helena Roerich, 2012, v. 1, p. 372).

This suggests that an important feature of a research approach is a researcher's spiritually developed consciousness.

A plethora of quotations from works of various authors can support this point of view but apparently the coherent system of judgments speaks for itself.

To sum it up, it is worthwhile to underline that according to the Teaching of Living Ethics, discovering new ways of world perception as well as cognition methods becomes real when man bases his cognitive desires on the principles of Love, Kindness, Beauty, Common Good with respect to the world and its Divine Origin. Thus, cognition is not considered here separately, in itself, but in indissoluble connection with life and inseparable from it cosmic evolutional meaning of Being which is understood as man's spiritual development. A more detailed account on this is enunciated in an author's earlier work.

\section{Conclusion}

To summarize the above stated the following should be noted. Understanding the principle of the Three-Hypostases Essence of the Foundations of Being and Cosmic laws of particularities of thinking resulting from it, as well as cognizing Heart as a universal energy centre of man's communication with superior Spiritual levels of Cosmos and the Foundations of Being will not only help to solve the problem of synthesis of research methodologies as instruments of natural, social sciences and the Humanities. Profound understanding of the ideas of the philosophy of total integrity which got the fullest and most systemic and integral revelation of their essence in the cosmic philosophy of the Teaching of Living Ethics will 
undoubtedly help mankind master the rules of harmonious life, find the ways out of global crises and optimize the process of their evolutional cosmic development.

\section{References}

Upanishads, (1992). A three-volume edition. In A.Y. Syrkin Translation from Sanskrit, the Foreword and the commentary. Moscow: Nauka.

Torchinov, E. A. (2005). The paths of philosophy of the East and the West: the knowledge of the beyond. SPb: Azbuka-classica, "Petersburg Oriental studies".

Viller, E. A. (2002). Doctrine of the One in antiquity and the middle ages. St. Petersburg: Aletheia.

Boehme, J. (1990). Aurora or Dawn in the ascent. Reprint ed. 1914. Moscow: Politizdat.

Bulgakov, S. N. (1993). The Tragedy of Philosophy. In Bulgakov, S. N (A two-volume edition. Vol. 1). Moscow: Nauka.

Kuhn, T. (2002). The Structure of Scientific Revolutions. Translation from English. Moscow: ACT.

Lakatos, I. (2002). Falsification and the methodology of scientific research programs. In Kuhn, T. The Structure of Scientific Revolutions. (pp .269-453). Moscow: ACT.

Popper, K. (2005). The logic of scientific research. Translated from Eng. Ed. V.N. Sadowski. Moscow: Respublica.

Einstein, A. (1967). About Science. Collection of scientific papers in four volumes. Volume 4. Moscow: Nauka.

Heisenberg, W. (2005). Part and whole. In Selected philosophical works: Steps to the horizon. St. Petersburg.

Bohr, N. (1961). Atomic Physics and Human Knowledge. Trans. from English. V. A. Fock \& A. V. Lermontova. Moscow.

Feyerabend, P. (1986). Selected papers on the methodology of science. Moscow: Progress.

Follmer, G. (1998). The evolutionary theory of knowledge. Translated from the German and the general wording: prof. A. V. Kezin. [DX Reader version] Retrieved from http://www. philosophy.ru/library/vollmer/vollmer.html

Mikeshina, L. A. (2006). The Philosophy of Science. (2nd ed.) Moscow: Publishing house of the International University in Moscow.

Taisina, E. A. (2013). Theory of knowledge. Introduction and Rondo capriccioso. SPb: Aleteja Helicopter-Media.

llyin, V. V. (2006). Methodology of social-humanity investigations. In S. A. Lebedev (Ed.). The Philosophy of Social Sciences and the Humanities. (pp. 69-151). Moscow: Academichesky Proyekt.

Lazarev, F. V. \& Lebedev S. A. (2006). Problem of truth in natural science, social sciences and humanities. In S. A. Lebedev (Ed.) The Philosophy of Social Sciences and the Humanities, (pp.11-68). Moscow: Academichesky Proyekt.

Soloviev, V. S. (1999). Philosophical Principles of Integral Knowledge. Minsk: Kharvest.

Blavatskaya, H. P. (1992). The Secret Doctrine. The synthesis of science, religion and philosophy. A two - volume edition. (Vols.1-2. Books 1-4). Moscow: Progress-Kultura.

Florensky, P. A. (2003). The Pillar and Foundation of the Truth: Experience of Orthodox Theodicy. Moscow: Publishing house AST.

Florensky, P. A. (2001). The watershed thoughts. In Christianity and culture. Moscow: FOLIO.

Berdyaev, N. A. (1994). The philosophy of the free spirit. Moscow: Respublica.

The Teaching of Living Ethics: Sheets of The Morya's Garden (2003). The first book: Call. The second book. Inspiration. Moscow: International Center of the Roerichs (ICR). Master-Bank; Community (Riga). (2004) Moscow: ICR, Master-Bank; Agni Yoga (Marks of Agni Yoga). (2008). Moscow: ICR, Master-Bank; Infinity. Part one. (2009). Part two. (2010). Moscow: ICR, MasterBank; Hierarchy, (2011) Moscow: ICR, Master-Bank; etc.

Roerich, H. I. (2000). On the Threshold of the New World. Moscow: ICR, Master Bank.

Letters of Helena Roerich. (2012) 1929-1938. Volume I. 1935-1939. Volume II. Translated by V. L. Dutko. Moscow: ICR, Master-Bank.

Roerich, N. K. (1995, 1996). Diary pages. (Vols. 1-3). Moscow: ICR, Master-Bank.

Shaposhnikova, L. V. (2004). Cosmic thinking and a new system of knowledge. In Cosmic outlook - new thinking of XXI century. Proceedings of the international scientific and public conference in 2003. (Vols. 1-3, V. 1). Moscow: ICR, Master-Bank.

Shaposhnikova, L. V. (2005). Historical and Cultural Peculiarities of the New Cosmic Thinking. In The United Scientific Centre of Problems of Cosmic Thinking. Moscow: ICR, Master-Bank.

Lebedenko, A. A. (2010). The philosophy of the heart in the history of Russian religious philosophy XI-XX centuries. Author's thesis. ... The candidate of philosophical sciences: 09.00.03. Moscow.

Maslin, M. A. (Ed.) (2007). Russian philosophy: Encyclopedia. Moscow: Algorithm.

Avotina, M. P. (2011). The Staff of the Traveller. Explanatory dictionary of concepts language books of Living Ethics. 2nd ed. SPb: LLC Publishing-polygraphic company "Costa".

Voyno-Yasenetsky, V. F. Spirit, Soul, Body. Retrieved from http://www.rait.airclima.ru/books/Spirit_Soul_and_Body.pdf

Galina Svyatokhina. (2013). The philosophy of cosmic thinking as research and as a life style. In XXIII World Congress of Philosophy: Philosophy as Inquiry and Way of Life. Athens, University of Athens, School of Philosophy, University Campus-Zografos. p. 709.

Galina B. Svyatokhina. (2013). The Philosophy of Cosmic Thinking as Research and as a Life Style. E-journal "Philosophy and humanities in information society" \# 2, p. 133-138. Saint Petersburg. Available: http://fikio.ru/wp-content/uploads/2013/06/ Filosofija-i-gumanitarnyie-nauki-v-informatsionnom-obschestve-2013-02.pdf.

Galina Svyatokhina. (2015). Living Ethics about spirituality and its evolutionary significance. The journal "Philosophy and culture". 2015. \# 2. p. 191-200. DOI: 10.7256/1999-2793.2015.2.14139.

Razumov, O. S. \& Blagodatskikh, V. A. (2006). System of knowledge: concepts, methodology, practice. M: Finance and statistics. 
This journal is printed for MCSER

by Gruppo Atena.net Srl

Via del Lavoro, 22,

36040, Grisignano VI, Italy

Tel: 0039/0444613696

Web: http:/ / www.atena.net 